\title{
SHELL NOUNS IN ENGLISH A PERSONAL ROUNDUP
}

\section{ELS ENCAPSULADORS EN ANGLÈS UNA SÍNTESI PERSONAL}

\author{
HANS-Jörg SCHMid \\ Ludwig-Maximilians-Universität München \\ hans-joerg.schmid@lmu.de
}

Abstract: This paper provides a somewhat personal retrospect on work on the notion and phenomenon of shell noun. After a brief introduction I will discuss some terminological and methodological issues. Following some remarks on the classification of shell noun uses I will then report on recent work into the origin and diachronic development of shell nouns and shell-noun constructions, and discuss a number of other advances in the study of shell nouns since their introduction in the rig9os.

Key words: shell noun, shell content, hypostatizing, semantic characterization, lexico-grammatical patterns.

Resum: Aquest treball ofereix una retrospectiva personal sobre la noció i el fenomen discursiu de shell noun (o encapsulador, literalment nom closca). Després d'una breu introducció, discutirem alguns aspectes terminològics i metodològics i efectuarem algunes remarques sobre la classificació dels usos dels encapsuladors. Finalment, aportarem una revisió d'investigacions recents sobre l'origen i el denvolupament diacrònic dels encapsuladors i de les construccions encapsuladores, i discutirem una sèrie de noves aportacions en l'estudi de l'encapsulació des de la introducció del concepte en els anys 90 del segle passat.

Paraules clau: encapsulador, contingut encapsulat, rë̈ficació, semàntica, patrons lexicogramaticals. 
HANS-Jörg SCHMID

Shell nouns in English - a personal roundup

\section{INTRODUCTION}

The aim of this paper is to provide a somewhat personal review of some basic issues revolving around the notion of shell noun. The main idea is to trace back the origins of the notion of shell nouns and the term itself and to discuss some insights and controversies regarding shell nouns that have emerged over the course of the 20odd years that the notion has been around. The problem is that only a limited number of aspects can be dealt with, giving rise to the challenge to select the most important ones. The reason why the preceding sentences are written in such a lousy style is that I am trying to illustrate the way shell nouns work in actual use: the examples given are the aim ... is to provide ..., the main idea is to trace back ..., the problem is that ..., the challenge to select ... and the reason why ... is that. In all cases, abstract nouns of the type aim, idea, problem, challenge and reason are used in the function of shell nouns, which, metaphorically speaking, encapsulate propositional content encoded in complementing clauses such as to provide a review of ... or that only a limited number of aspects ... . This propositional content is referred to as shell content (Schmid 2000).

The paper is divided into 6 sections. The second section gives a short historical review of the term shell noun and provides a definition of the notion of shell nouns and some suggestions concerning how to operationalize it. Section 3 looks at the classification of shell nouns, and Section 4 reports some findings concerning the origins of shell nouns in English and their diachronic development. Section 5 discusses recent advances relating to genre-specificity, language pedagogy, computational linguistics and linguistic theory. Section 6 wraps up the paper by praising the editors for having put together such an impressive volume.

\section{SHELL NOUNS: THE TERM AND THE IDEA}

\section{I THE ORIGIN OF THE TERM shell nOUn AND SOME EARLY RESEARCH}

The term shell noun occurred to me in late 1995. Its first public test runs took place in talks in the linguistic colloquia or linguistic circles of the universities of Munich, Oxford, Birmingham and Lancaster that I gave in 1996 and early 1997, and in presentations at the 16th International Congress of Linguists in Paris in 1997 and the 5th International Cognitive Linguistics Conference in Amsterdam in 1998. The two conference presentations were eventually published as Schmid (1998) and (1999), respectively. Hunston and Francis (2000: 185) were the first to adopt the term, 
but failed to acknowledge its source. Schmid (2000) was the first volume-sized study on shell nouns. Flowerdew and Forest (2015) recently published a second monograph on the topic, preferring the term signalling noun apparently introduced by Flowerdew as early as 1994 (see Flowerdew and Forest 20I5: xv). Benitez-Castro (2015) provides a recent critical survey of insights into shell noun phrases.

The linguistic phenomenon captured by the term shell noun was of course noticed before I introduced the term itself. The metaphor behind the term, i.e. the idea that the nouns 'contain' or 'encapsulate' conceptual content, was already presaged in the work by Vendler (1968: 78-82), Francis (1986: 36-38; 1994: 85) and Conte (1996). The signalling, linking and characterizing functions had been recognized by Winter (1977), Francis (1986), Ivanič (199I), and Flowerdew (see Flowerdew and Forest 20I5: xv), among others. Surveys of the wide range of notions which are more or less equivalent to the term shell noun but which highlight different aspects can be found in Benitez-Castro (2015: 174) and Flowerdew and Forest (2015: 9).

\subsection{HOW SHELL NOUNS ARE DEFINED}

From the earliest publications which use the term shell noun (Schmid 1998, I999, 2000) onwards, the notion is defined in functional terms. It is not an inherent property that determines whether or not a given noun belongs to the class of shell nouns, but instead a set of functions the noun serves when used in actual discourse. The abstract nouns in question - e.g. fact, idea, problem, aim, plan and many others can be used as shell nouns, but they can also be used in different functions. However, not all nouns, in fact not even all abstract nouns, can function as shell nouns. For a given noun to lend itself for use in shell-noun function, it must meet the requirement that it open up an inherent semantic gap that must be filled by information from the linguistic context (cf. Schmid 2000). A somewhat trivial but perhaps helpful analogy to explain this comes from the field of food, more specifically from various types of potatoes. On the one hand, we can categorize potatoes in terms of inherent features such as species, size, texture, season, taste or colour. These types of potatoes, e.g. Russet, floury, waxy, new, sweet, red, etc., would correspond to word class categories like nouns and verbs, or subtypes of nouns such as concrete, abstract, mass or count nouns. The functional aspect, on the other hand, comes into play when we consider how we select different types of potatoes for different dishes: while floury potatoes of any size can go into mashed potatoes, only large floury potatoes are useful for making baked ('jacket') potatoes; potato salad requires the use of waxy potatoes, while buttered boiled potatoes are particularly good when new potatoes are available. The 
notion of shell noun corresponds to notions such as 'jacket potato', 'chipped potatoes' or 'buttered potatoes': their defining feature derives from the way they are used in actual context with a specific purpose in mind, but their inherent properties - the semantic gap in the case of shell nouns and the specific size, texture and season in the case of potatoes - earmark them to varying degrees to be used in this particular way.

What, then, are the functional properties that distinguish shell nouns? According to Schmid (2000: 15), three functions on three levels of description are crucial:

I. On the cognitive level, shell nouns serve an encapsulating function by contributing to the formation of temporary thing-like concepts. This function derives from the hypostatizing potential of nouns, i.e. their potential to suggest the existence of a bounded thing-like entity. The hallmark of shell nouns - in contrast to other nouns - is that the specific concepts they encapsulate are local, to a large part context-specific and therefore transient. What is characterized as a problem, challenge or aim changes from one use of these nouns to the next, depending on the proposition encoded in the surrounding linguistic context, i.e. the shell content.

2. On the level of meaning, shell nouns serve the semantic function of characterizing the propositional content encoded in the linguistic cotext. For example, the use of the noun problem in the introductory paragraph characterizes the proposition 'only a limited number of aspects can be dealt with' as an obstacle, the noun challenge the proposition 'select the most important ones' as a difficult task. The characterizing potential is not transient in the way the encapsulating one is. It is part of the lexical rather than the contextual meaning of nouns and can vary from extremely generic, e.g. in the nouns thing, fact, case, situation or event, to quite specific, e.g. in disadvantage, reassurance or peculiarity.

3. On the level of discourse, shell nouns serve a linking and referring function by instructing readers and hearers to bind the semantic characterization provided by the noun with that encoded as shell content. Shell nouns thus share with deictic elements their ability to refer to contextually determined targets of reference, but in contrast to typical deictic elements such as personal or demonstrative pronouns, they include, by virtue of their characterizing and encapsulating function, a noticeable symbolic potential in addition to the referring or pointing one. This potential emerges most clearly if one compares shell noun uses in anaphoric reference such as this idea must be pursued or that problem must be solved to isolated uses of demonstratives as 
HANS-Jörg SCHMID

heads of noun phrases, i.e. this must be pursued or that must be solved alone. Referring back to a previously mentioned proposition by this alone misses the opportunity of characterizing the given proposition in a specific way and of turning it into a thing-like and yet ephemeral entity established in discourse space.

These defining features are widely accepted in later work on shell nouns and related notions (see Section 2.I for references).

\subsection{HOW THE DEFINITION CAN BEEN OPERATIONALIZED}

It is one thing to provide a theoretical definition of a notion and another to determine how actual manifestation of the phenomenon can be identified, both systematically, that is, for example, with the aim of creating automatic or semi-automatic queries in corpora, and locally, i.e. when it comes to deciding for a given token of a noun whether or not it is an example of usage in shell noun function. Definition and operationalization are sometimes confused in the literature on shell nouns and related phenomena. For example, Flowerdew and Forest (20I5) directly contrast their own definition of signalling nouns in terms of «equative encapsulation with lexical specifics provided elsewhere in the text» (Flowerdew and Forest 20I5: 48) with «the syntactically driven position of e.g. Schmid (2000)». In doing so, they seem to confuse definition and operationalization, since Schmid (2000: 14-2I) defines shell nouns in terms of the functional characteristics repeated here (among them first and foremost the encapsulating one). Grammatical patterns are explicitly used as a means of operationalizing by Schmid (2000), but do not serve as a definition.

Ideally, it should of course be possible to derive the operationalization more or less directly from the definition and the selection and exclusion criteria it contains. In doing so, the following considerations are of key importance.

First, only nouns can function as shell nouns. This criterion is required because the specific encapsulation potential attributed to shell nouns, viz. the potential to hypostatize and reify, hinges upon the resulting conceptualization as 'thing'-like entity (Langacker 1987b: 189). While anaphoric pronouns like this and that in the function termed «extended reference» and «reference to fact» by Halliday and Hasan (1976: 52-53, 66-67) also have the ability to instruct hearers and readers to select and re-activate complex propositional content (rather than singular entities introduced by referring noun phrases), they fail to accomplish the strong concept-forming effects (Leech 198I) achieved by the use of nouns. 
Second, only uses of nouns which open up a semantic gap to be filled by information from the linguistic context can function as shell nouns. The relation between shell noun and shell content has been described as «experiential identity» (Schmid 2000: 23). This somewhat cumbersome term is meant to indicate that the speakers or writers who select a given shell noun actually portray the shell noun phrase and the proposition encapsulated as shell content as referring to the same discourse representation. Whether there is a strict logical relation of identity is a different matter. The relation of experiential identity shows most clearly on the linguistic surface in so-called «identifying» (Halliday and Matthiessen 2004) or «equational» constructions (Langacker 1987a: 77) in which shell noun and content are connected by a form of the verb $B E$, e.g. the aim is to provide a review or the problem is that only a limited number of aspects can be dealt with. It is, however, also active in other patterns. Interestingly, in the example The reason why the preceding sentences are written in such a lousy style is that I am trying to illustrate the way shell nouns work in actual use used above, the noun reason enters into two relations: one with the that-clause functioning as subject complement following the verb form is, and another one with the complementing why-clause. Only the former stands in a genuine relation of experiential identity, since the that-clause actually provides the motivation for an action (trying to illustrate ...), while the why-clause actually encodes the outcome of the explanatory quasi-causal relation established by the noun reason. Flowerdew and Forest (2015: 55) refer to cases of this type as «bivalent signalling nouns» and also remark that only one of the two relations is «strictly equative».

Third, a limited number of lexico-grammatical patterns are particularly suitable for encoding the link of experiential identity between shell noun and shell content. These are listed in Table I:

\begin{tabular}{l|l}
\hline Patterns & Examples \\
\hline $\begin{array}{l}\text { a. Shell NP }+\mathrm{BE}+\text { complementing that-clause, } \\
\text { to-infinitive clause or interrogative clause }\end{array}$ & $\begin{array}{l}\text { The problem is that I have to leave now. } \\
\text { The idea is to have fun. } \\
\text { The question is why you have to leave. }\end{array}$ \\
\hline $\begin{array}{l}\text { b. Shell NP + postnominal that-clause, to- } \\
\text { infinitive clause or interrogative clause }\end{array}$ & $\begin{array}{l}\text { The fact that I have to leave ... } \\
\text { The aim to have fun ... } \\
\text { The question why you have to leave ... }\end{array}$ \\
\hline c. Referring item $(+$ premod $)+$ shell noun & This (wonderful) idea must convince them all. \\
\hline d. Referring item + BE $(+$ premod $)+$ shell noun & This is a wonderful idea. \\
\hline
\end{tabular}




\begin{tabular}{l|l}
\hline e. Shell NP + of-PP & $\begin{array}{l}\text { The notion of love ... } \\
\text { The idea of having fun ... } \\
\text { The question of why you have to leave ... }\end{array}$ \\
\hline $\begin{array}{l}f . \quad \text { it is }(+ \text { premod })+\text { shell NP + that-clause or } \\
\text { to-infinitive }\end{array}$ & $\begin{array}{l}\text { It is a great idea to go out and have fun. } \\
\text { It is a quite a big problem that I have to leave. }\end{array}$ \\
\hline
\end{tabular}

Table I: Lexico-grammatical patterns typical of shell noun constructions

Two aspects must be considered when assessing the patterns in Table I. The first concerns the extent to which a given pattern selects and is thus predictive of abstract nouns in shell noun function. In this respect, patterns a. and b. stand out from the others by providing the kind of environment in which shell nouns thrive. It is precisely for this reason that I used these patterns as diagnostic criteria and query patterns in Schmid (2000). In fact, other patterns like e. were also taken into consideration (see e.g. the references in the tables on pp. 294-297 of Schmid 2000), but they were not targeted by automatic searches because their cue validity for shell-nounhood is much weaker: A large variety of both abstract and concrete nouns can be found in patterns c., d. and also e., which renders it much more difficult to use these patterns as indicators for shell noun function or as a basis for search queries. Pattern e., the sequence of NP of NP, has a particularly low predictive potential, since the preposition of is highly polysemous and frequently encodes a possessive or part-whole relation (as in the roof of the house or the heart of the matter) rather than one of identity. Therefore, its cue validity as a predictor for the occurrence of a shell noun is comparatively low, which of course is not to say that it does not produce good examples of shell noun uses. While it has been claimed that this pattern is neglected in the study by Schmid (2000), a look at the entry "of-prepositional phrase» in the index of subjects of this book partly refutes this claim.

A second reason why patterns $\mathrm{a}$. and $\mathrm{b}$. stand out from the list in Table $\mathrm{I}$ is that the choice of the type of complementing clause, i.e. that-clause, infinitive clause or wh-clause, is not random, but instead is mainly determined by the meaning of the given noun and the ontological status of the proposition encoded as shell content in terms of abstract state of affairs, event, action or process. This is further evidence of the fact that there is a particularly close tie between these two patterns and shell noun usage. As shown in some detail in Schmid (2000; see the summary on pages 294-297), most nouns select only one type of complement clause, while some allow the choice of several depending on the current meaning and the ontological nature of the shell content.

Caplletra 64 (Primavera, 2018), pp. 109-128 
The patterns listed in Table I also differ in terms of their potential to fulfil additional functions over and above the three defining ones given above. The main feature of patterns $d$. and $f$. is that the premodifying adjectives that they frequently include allow speakers to add further evaluations and descriptions that highlight their stance towards what is encoded as shell content. Patterns a. and f. allow speakers and writers to highlight the shell content in prominent position at the end of the sentence. Pattern a. additionally topicalizes the characterization contained in the shell noun by fronting the shell noun and by virtue of the existential presupposition triggered by the definite noun phrase, which suggests that this characterization must be taken for granted (Schmid 200I). Since this existential presupposition is much stronger when the shell noun phrase has definite reference, shell noun uses with indefinite articles strongly reduce the encapsulating effect (Benitez-Castro 20I4: I89; Schmid 20oo). Pattern $f$. is a double-focus construction highlighting both the shell noun and the shell content for attention. Patterns c. and d. differ from the others in that the links they establish usually reach out beyond the limits of clauses and sentences. The contribution of these patterns to discourse coherence is therefore particularly strong (see also Flowerdew and Forest 20I5: ch. 4).

\section{THE CLASSIFICATION OF SHELL NOUNS}

In Schmid (2000), I proposed a classification of shell nouns into six broad categories, all of which were further sub-categorized into groups as shown in Table 2:

\begin{tabular}{llll}
\hline Classes & Groups & Examples & $\begin{array}{l}\text { Preferred } \\
\text { complement type }\end{array}$ \\
\hline \multirow{3}{*}{ Factual } & Neutral & thing, fact, phenomenon & \\
& Causal & reason, result, upshot & \\
& Evidential & evidence, proof, sign & that-clause \\
& Comparative & difference, similarity & \\
& Partitive & aspect, part, example & \\
& Attitudinal & problem, advantage, irony & \\
\hline
\end{tabular}


HANS-JÖRG SCHMID

Shell nouns in English - a personal roundup

\begin{tabular}{|c|c|c|c|}
\hline Linguistic & $\begin{array}{l}\text { Propositional } \\
\text { Illocutionary }\end{array}$ & $\begin{array}{l}\text { news, argument, rumour } \\
\text { statement, question, order, offer, } \\
\text { complaint }\end{array}$ & $\begin{array}{l}\text { that-clause } \\
\text { dependent on type } \\
\text { of illocution }\end{array}$ \\
\hline \multirow{5}{*}{ Mental } & Conceptual & idea, theory, notion, mystery & that-clause \\
\hline & Creditive & belief, knowledge, view, illusion & that-clause \\
\hline & Dubitative & doubt, question, disbelief & that-clause \\
\hline & Volitional & aim, plan, solution & to-infinitive \\
\hline & Emotive & surprise, regret, delight, fear, worry & that-clause \\
\hline \multirow{3}{*}{ Modal } & Epistemic & possibility, danger, truth, reality & that-clause \\
\hline & Deontic & permission, mission, need & to-infinitive \\
\hline & Dynamic & $\begin{array}{l}\text { ability, capacity, opportunity, destiny, } \\
\text { fate }\end{array}$ & to-infinitive \\
\hline \multirow{3}{*}{ Eventive } & General & event, act, situation & \multirow{3}{*}{ to-infinitive } \\
\hline & Specific & attempt, effort, struggle, priority & \\
\hline & Attitudinal & trouble, problem, success, mistake & \\
\hline \multirow{2}{*}{ Circumstantial } & General & situation, context, position & \multirow{2}{*}{ varied } \\
\hline & Specific & place, time, way, procedure, provision & \\
\hline
\end{tabular}

Table 2: Classes and groups of shell noun uses with preferred complement types (adapted from Schmid 2000: 294-297)

This classification was mainly based on the meanings of the nouns themselves, but it was also supported by their preferences for the different types of complements listed in the right-hand column. It must be emphasized that these preferences are indeed what the term suggests, i.e. tendencies rather than strict rules. More detailed investigations of the whole field of shell nouns (e.g. Flowerdew and Forest 20I5) or of specific classes such as different types of illocutionary nouns (Vergaro 2015, 2018; Vergaro and Schmid 20I7) have shown that nouns collected in one class or group can show considerable variation regarding their complementing options, restrictions and tendencies. The general trend, summarized in Schmid (2000: 293), is that to-infinitives are selected for the complementation of nouns encoding aspects such as 'manipulation' (Givón 1990), 'wanting' (Wierzbicka 1988) or the so-called «de re» domain of

Caplletra 64 (Primavera, 2018), pp. 109-128 
actions and events (Frajzyngier and Jasperson 1991), while that-clauses complement nouns encoding aspects such as 'knowing', 'believing', 'saying' or the 'de dicto' domain.

The six classes in Table 2 can be divided into two large sections with regard to their representativeness of the class of shell nouns. The first section comprises the first four classes, i.e. factual, linguistic, mental and modal nouns, which can generally be considered to produce highly typical shell noun uses. These are characterized by a clear link of experiential identity, by relatively strong - though, of course, highly varied - reliance on the dominant patterns a. and b. in Table $\mathrm{I}$, and by encapsulation of abstract states of affairs rather than actions or events. The second section comprises eventive and circumstantial nouns which can be considered as less good or even marginal shell noun uses on the basis of these criteria.

Both the classification rendered in Table 2 as such and the differentiation of shell noun uses into prototypical and less typical or even peripheral cases have received support from the recent study by Flowerdew and Forest (2015), who arrive at a conceptually very similar, though terminologically divergent classification, although they start out from different theoretical assumptions and take a discourse-oriented approach including a stronger qualitative component. With regard to the classification into six categories, the authors (Flowerdew and Forest 2015: 29) state the following:

Schmid's categories broadly correspond to our own, although the basis of our system in systemic functional grammar leads us to apply different probes for class membership, which has the effect that we would include some items within different categories than Schmid (e.g. agreement, deal, contract, compromise, pact as locution rather than mental - see Schmid 2000: 224-6). That said, the general correspondence of our classification schemes lends support to both Schmid's system and our own. It is noteworthy that we have arrived at similar conclusions while working from different starting points.

Concerning assessments of typicality, Flowerdew and Forest (2015: 9I) conclude:

In spite of the very different methods used to arrive at the lists, there is a fairly good match between Schmid's examples of prime shell nouns and our list of most frequent SNs in the corpus (those that occur more than Ioo times): fact, idea, issue, principle, problem, reason, thing all occur among our most frequent SNs, and all are found in Schmid's list of prototypical shell nouns.

These convergences between Schmid (2000) and Flowerdew and Forest (2015) are complemented by others. Of particular interest are Flowerdew and Forest's (2015: I65-I67, I85) observations on similarities and mutual support between the two approaches with regard to the distribution of the lexico-grammatical patterns on which 
both studies collect systematic data. Like Flowerdew and Forest, I regard these convergences as both remarkable and mutually gratifying, especially in view of the fairly harsh criticism vented by Flowerdew (2003) in his review of Schmid (2000).

Jiang and Hyland (2015: 6) claim that the semantic classification proposed in Schmid (2000) falls short of doing justice to the attitudinal function of shell nouns (which they refer to as stance nouns in order to emphasize this function). They support their claim by means of an example:

Thus, for him [i.e. Schmid], the noun 'advantage' falls into the factual group presenting the complement information as uncontested. Unfortunately, this overlooks its role in conveying a writer's positive evaluation of an entity or action (Jiang and Hyland 2015: 6)

Given that my definition of shell noun explicitly rests on the function of characterization (see Section 2.2 above), this critique seems out of place. With regard to nouns like advantage in particular, Schmid (2000: I26-I27) makes it very clear that "[s]peakers use them to portray facts as facilitating progress towards an aim», and that the noun advantage itself allows speakers to «construe a state of affairs as favourable and as giving rise to a positive attitude». Indeed, nouns like problem, trouble, benefit and many others, including advantage, are classified as «attitudinal factual nouns» in Schmid (2000: I2O-I30), which shows that the 'stance' potential of these nouns was hardly «overlooked", as Jiang and Hyland claim in the passage quoted above and in the abstract of their paper (20I5: I).

\section{THE ORIGIN AND HISTORY OF SHELL NOUNS AND SHELL-NOUN CONSTRUCTIONS}

The only studies I am aware of which have tackled the historical origins and diachronic development of shell-noun constructions are Mantlik (2OII) and (2013), as well as Schmid and Mantlik (2015). The first of these boasts the widest scope by far, but has unfortunately not yet been published. It may therefore be of interest to summarize the major findings here, some of which are also reported in Mantlik (2013).

As far as its methodology is concerned, the study by Mantlik (20II) is based on an extensive survey of the entries on the 670 shell noun types listed by Schmid (2000) in the Oxford English Dictionary $(O E D)$, of data extracted from existing historical corpora such as the Helsinki Corpus, and, importantly, on the quotation database of the $O E D$, which contained considerable numbers of attestations of shell noun uses predating those found in the entries for shell noun types.

Caplletra 64 (Primavera, 2018), pp. 109-128 
HANS-JöRG SCHMID

Shell nouns in English - a personal roundup

According to Mantlik (20II), the first shell noun uses crop up in the Middle English period. Attestations from Old English were not found. The first attestations of nouns in the four major patterns listed in Table I are provided in Table 3:

\begin{tabular}{llll}
\hline Pattern & Noun & First attestation & Source \\
\hline shell NP $+\mathrm{BE}+$ to-infinitive & reason & $\mathrm{c} 1230$ & Anon., Ancrene Riwle \\
shell NP + that-clause & point & $\mathrm{c} 1230$ & Anon., Ancrene Riwle \\
shell NP + to-infinitive & reason & a1300 & Anon., Cursor Mundi \\
shell NP + BE + that-clause & desire & c1451 & John Capgrave, Life St. Gilbert \\
\hline
\end{tabular}

Table 3: First attestations of major lexico-grammatical patterns hosting shell noun (Mantlik 20II)

Mantlik (20II) links up the dates of first attestation with the insight that the nouns that are attested first are all loan words from Romance and the insight that equivalents of shell-noun uses existed in Latin and French. This brings her to the tentative conclusion that it is likely that the typical patterns, which she calls «shell-noun constructions» (see Section 5.4), were borrowed from French and/or Latin.

As far as the etymological origin of the nouns that serve as shell nouns themselves are concerned, the detailed analysis of the information provided by the $O E D$ reveals that more than three quarters $(77.46 \%)$ of the nouns are borrowed from Romance or Greek, while less than Is percent (I4.62) are of Germanic origin. The etymology of 7.9I percent could not be determined unambiguously. Although it is well known that a considerable proportion of all English words are not of Germanic origin, a comparison to existing counts and extrapolations of the distribution in the whole lexicon (for example by Scheler 1977) indicates that loan words are strongly overrepresented in the field of shell noun candidates. This corroborates the hypothesis that shell noun constructions are associated or at least strongly reinforced by the influx of Latin and French in the Middle English period.

Mantlik (20II) also investigated the history of shell nouns from the perspective of morphology and word-formation. This analysis was motivated by Schmid's (2000: I48) claim that many shell nouns are derived from verbs by means of suffixation and conversion. The latter part of this claim, i.e. the one relating to conversion, is refuted by Mantlik (20II). She shows that in two thirds of the cases where shell nouns have verbal counterparts the nouns are attested before the verbs. In only $19 \%$ of the cases could it be ascertained that the verbs existed before, in $5 \%$ verbs and nouns are first attested at the same time (with the remaining IO\% defying an unambiguous analysis). This is a very interesting finding, because the parallel to overtly marked suffix-derivations such 
as agreement or announcement would suggest that the numerous converted forms such as aim, attempt, desire, plan and many others would also be deverbal nominalizations.

A further aspect of key interest that Mantlik (20II) researched concerns diachronic changes regarding the mutual relations between shell nouns and their typical patterns. This concerns the questions whether shell nouns undergo a development in terms of the patterns they rely on, on the one hand, and whether shell-noun patterns undergo a development in terms of the nouns they attract, on the other. Both types of developments take place, and both were found to be very common indeed. Nouns typically start out with one type of complementation and only later conquer new patterns, sometimes over the course of centuries. The noun answer, for example, is first attested in the pattern shell NP + that in 1375 , followed by the patterns shell $\mathrm{NP}+\mathrm{BE}+$ that in 1565 and shell $\mathrm{NP}+\mathrm{BE}+$ to in 1657 . The pattern shell $\mathrm{NP}+$ to is not attested. Conversely, patterns often begin by attracting a fairly narrow selection of nouns before opening up to a wider range. However, the opposing trend is also observed, when nouns that did rely on a pattern for some time come to be rejected. Schmid and Mantlik (2015: 579-99) provide a detailed description of the way in which the pattern shell NP $+\mathrm{BE}+$ that-clause changed the type of nouns it attracts from action-related and event-related ones encoding deontic modality and directive illocutionary acts to nouns of reporting and asserting. Many of the earlier nouns, for example purpose, will or request, are usually no longer complemented by that-clauses in Present-Day English, but rather by to-infinitives exclusively. What is also remarkable is the fluctuation of nouns that, metaphorically speaking, enter or leave the construction. As many as 133 of the 293 nouns that Schmid and Mantlik (2015: 595) found to occur in the pattern shell NP + BE + that-clause between 1384 and 1870 occurred only once, which means they remained hapax legomena as shell nouns in the database. As many as I60 nouns registered in the database are obsolete in Present-Day English (Schmid and Mantlik 20I5: 596).

\section{FURTHER ADVANCES IN THE STUDY OF SHELL NOUNS}

Since its inception in the 1990s, the study of shell nouns has branched out into various fields. I will briefly discuss the most important ones in this penultimate section of the paper.

Caplletra 64 (Primavera, 2018), pp. 109-128 
HANS-Jörg SCHMId

Shell nouns in English - a personal roundup

\section{I SHELL NOUN USAGE IN DISCOURSE IN DIFFERENT GENRES}

That the functions and usage frequencies both of shell nouns in general and of specific types of shell nouns are genre-specific became obvious in all of the early studies into this phenomenon. Due to the lack of space, I cannot mentioned the large body of studies on shell nouns in various text-types and genres and on the preferred choice on nouns depending on genre and field of research. A very useful survey of studies on genres of academic writing and speech in different domains, both by LIspeakers and L2-learners, is provided by Benitez-Castro (20I4: 178). Using a manual corpus-based method, Benitez-Castro (20I4: I86-88) confirms in his own research for a selection of 42 shell noun types that these are found considerably more frequently in writing than in speech, but also finds that the distribution is similar to that of nouns in general. The author also notes that within the various spoken genres, conversations and meetings stand out with higher relative frequencies. However, as he rightly points out, for casual conversation this is mainly due a small number of shell nouns types, presumably not only thing, as is mentioned by him, but also time and way.

Based on a manual inspection of a systematically designed corpus, Flowerdew and Forest (2015) show that shell noun use in academic texts varies in terms of genres (lectures, journals, textbooks) and domains, viz. various natural sciences (biology, chemistry, physics, ecology, engineering science) and social sciences (economics, business, politics and international relations, sociology and law). Among many other things, they find that shell nouns occur significantly more frequently in texts in the domain of social sciences than in those on natural sciences. The authors assume "that this may be due to the greater use of technical terms in the latter division, terms which do not require lexical specification in scientific discourse and so are not counted as SNs in this study" (Flowerdew and Forest 2015: 183). Convincing as it may sound, this explanation distracts from the fact that shell nouns (or signalling nouns) serve special discourse functions, mainly linking encapsulation, which cannot simply be taken over by technical terms. This means that the two types of nouns are unlikely to enter into an onomasiological competition in a given production situation. Therefore, I consider it likely that other factors, e.g. the somewhat terser and formulaic style typical of natural science writing, including a lower degree of reliance on and need for marking of complex coherence relations, and the more technical content (rather than the choice of technical vocabulary itself) also play a role.

The role of shell nouns in establishing text deixis in narrative sequences was investigated by Ribera (2007). Comparing the Catalan translation of an English text, Ribera finds that the former shows a higher frequency of text-deictic expressions, and he discusses the potential changes in perspective caused by this. 


\subsection{SHELL NOUNS IN LANGUAGE PEDAGOGY}

The fields of language teaching and L2-learner production have been particularly receptive to the idea of shell nouns (and related notions). A good example is the study by Aktas and Cortes (2008), who compare the use of shell nouns in academic prose produced by experts and learners. They find that

[i]n spite of the fact that the student writers in this investigation used a wide variety of shell nouns, they did not use some of them in the same patterns or to convey the same functions used by published authors, particularly in the case of fact. These students do not need to be taught these nouns as vocabulary items. They need to be exposed, taught, to examples that illustrate the cohesive functions of shell nouns when used in the appropriate lexico-grammatical patterns to help them more efficiently organize the communicative purpose of their texts. (Aktas and Cortes 2008: 13)

Flowerdew (2006, 2010) shows that Cantonese learners of English differ from Li writers in terms of the frequency and accuracy of their use of shell nouns, and that their proficiency correlates quite well with their ability to use shell nouns. Since learners generally make use of a much smaller range of shell noun types, he suggests that particular attention be paid not only to encouraging students to use shell nouns more often in their academic texts, but also to teaching the cohesive potential of different groups and items. Paquot (2007) makes a similar plea.

\subsection{COMPUTATIONAL APPROACHES TO THE STUDY OF SHELL NOUNS}

Their functional nature and their dependence on context render shell nouns an interesting challenge for Natural Language Processing. The main goal of computational approaches has therefore been to identify shell nouns by computational means in authentic text and to capture their contribution to cohesion and coherence by devising automated ways of resolving their antecedents in anaphoric and cataphoric uses (Kolhatkar et al. 20I3; Kolhatkar and Hirst 2014; Kolhatkar 2015). Simonjetz and Roussel (2016) propose a scheme for the manual annotation of shell nouns and single and multiple shell contents associated with them in order to contribute to improving the quality of identification procedures in English and other, grammatically more flexible languages such as German. 
HANS-JöRG SCHMID

Shell nouns in English - a personal roundup

\subsection{THEORETICAL ADVANCES IN THE STUDY OF SHELL NOUNS}

Most studies of shell nouns have taken the typical lexico-grammatical environments in which shell nouns occur (see Section 2.3 above) into consideration. While these environments were often just described in general grammatical terms as recurrent patterns, the advent of construction grammar (see, e.g. Goldberg 1995, 2006; Hilpert 2014) has left a strong impact on how researchers understand the relation between shell nouns and their lexico-grammatical environment. One key tenet of Construction Grammar is that both non-compositional and frequent compositional lexico-grammatical patterns are represented as entrenched and conventionalized form-meaning pairings linked by symbolic associations comparable to lexical items. Following up on earlier suggestions by Ungerer and Schmid (2006: 248-50), Schmid (2007) made a more explicit case for treating combinations of shell nouns and shell contents in the typical lexico-grammatical patterns as «shell-content constructions». As mentioned above, Mantlik (2OII) uses the term «shell-noun construction». The key argument put forward is that the different patterns convey meanings that go beyond the joint contribution of the lexical meanings of the nouns and the grammatical meanings that can be attributed to the different complementation patterns. Using the shell $\mathrm{NP}+\mathrm{BE}+$ to-infinitive pattern as an example, Schmid (2007) shows that semantic clusters such as 'means', 'internal motivation', 'obligation' and 'intended result' have become established as lower-level schemas whose meanings can rub off onto general nouns that do not carry these meanings as part of their lexical semantic setup.

In line with general assumptions in construction grammar, it can be argued that shell-content or shell-noun constructions form a hierarchically arranged network of more general constructions, such as the $\mathrm{N}+\mathrm{BE}+$ to-construction (Schmid 2007) or the $\mathrm{N}+\mathrm{BE}$ - that-construction (Schmid and Mantlik 20I5), and more specific ones, e.g. the factual, attitudinal, linguistic or modal variant of the $\mathrm{N}+\mathrm{BE}+$ that-construction. Schmid and Mantlik (20I5) show that different writers in the history of English had different preferences for such variants. For example, Samuel Pepys mainly used the $\mathrm{N}+\mathrm{BE}+$ that-construction with speech-reporting nouns (news, talk, discourse) in order to record the rumours of the day in his diary, while Samuel Richardson had a penchant for emotive and attitudinal nouns (fear, consoliation, hope, desire) that were useful for talking about the emotional turbulences suffered by his female protagonists. Treating patterns of shell noun uses as constructions thus has advantages for understanding the collocational and colligational preferences that can be observed in terms of so-called collostructions (Schmid and Küchenhoff 2013; Stefanowitsch and Gries 2003) and for explaining diachronic change, e.g. with regard to the combinatorial constraints and 
tendencies of shell nouns and complementation patterns, as an example of the wider phenomenon of constructional change (Hilpert 2013; Traugott and Trousdale 20I3). This also explains why such changes, for example, the tendency towards omission of the complementizer that in the $\mathrm{N}+\mathrm{BE}+$ that construction for a limited set of nouns like truth, thing, point and problem (Mantlik and Schmid forthcoming), do not proceed in a random fashion, but rather follow semantic pathways.

\section{CONCLUSION}

Shell nouns are marked by a unique combination of semantic, cognitive and discourse-related functions and characteristics. This opens up a variety of perspectives for research that aims to elucidate how texts and discourse work and how the mind combines information encoded in different parts of sentences and even portions of discourse. The papers collected in this volume testify to the unabated interest in shell nouns not only in English, but increasingly also in other languages. I would like to thank the editors for coming up with the idea of devoting a volume to recent research on shell nouns and congratulate them on collecting such an impressive array of exciting papers.

\section{REFERENCES}

Aкtas, R.N. \& V. Cortes (2008) «Shell nouns as cohesive devices in published and ESL student writing», Journal of English for Academic Purposes, 7 (I), pp. 3-I4. Benitez-Castro, M.-A. (20I4) «Formal, syntactic, semantic and textual features of English shell nouns: a manual corpus-driven approach", in A. Alcaraz-Sintes \& S. Valera-Hernández (ed.), Diachrony and synchrony in English corpus linguistics, Bern etc., Peter Lang, pp. I7I-203.

Benitez-Castro, M.-A. (20I5) «Coming to grips with shell-nounhood: A critical review of insights into the meaning, function and form of shell-noun phrases", Australian Journal of Linguistics, 35 (2), pp. I68-94.

Conte, M.-E. (1996) «Anaphoric encapsulation», Belgian Journal of Linguistics, Io, pp. I-IO.

Flowerdew, J. (2003) «Review of Schmid, Hans-Jörg, English abstract nouns as conceptual shells. From corpus to cognition, 2000, Mouton», International Journal of Corpus Linguistics, 8 (2), pp. 313-22.

Caplletra 64 (Primavera, 2018), pp. 109-128 
HANS-JÖRG SCHMID

Shell nouns in English - a personal roundup

- (2006) «Use of signalling nouns in a learner corpus», International Journal of Corpus Linguistics, II (3), pp. 345-62.

- (2010) "Use of signalling nouns across Li and L2 writer corpora», International Journal of Corpus Linguistics, I5 (I), pp. 36-55.

Flowerdew, J. \& R. W. Forest (2015) Signalling Nouns in English: A Corpus-Based Discourse Approach, Cambridge, Cambridge University Press.

Frajzyngier, Z. \& R. Jasperson (I99I) «That-clauses and other complements», Lingua, 83 (2), pp. $133-53$.

Francis, G. (1986) Anaphoric nouns. Discourse Analysis Monographs II, Birmingham, University of Birmingham Printing Section.

- (1994) «Labelling discourse: An aspect of nominal-group lexical cohesion», in M. Coulthard (ed.), Advances in written text analysis, London, Routledge, pp. 83-IOI.

Grvón, T. (1990) Syntax: A functional-typological introduction. Volume 2, 2 vol., Amsterdam/Philadelphia, Benjamins.

GoldBerG, A. E. (1995) Constructions: a construction grammar approach to argument structure, Chicago, University of Chicago Press.

- (2006) Constructions at work: the nature of generalization in language, Oxford / New York, Oxford University Press.

Halliday, M. A. K. \& R. Hasan (1976) Cohesion in English, London, Longman.

Halliday, M. A. K. \& C. M. I. M. MatTHiessen (2004) An introduction to functional grammar 3 rd ed., London / New York, Arnold.

HiLPert, M. (2013) Constructional change in English: developments in allomorphy, word formation, and syntax, Cambridge, Cambridge University Press.

- (2014) Construction grammar and its application to English, Edinburgh, Edinburgh University Press.

Hunston, S. \& G. Francis (2000) Pattern grammar: A corpus-driven approach to the lexical grammar of English, Amsterdam, John Benjamins.

IVANIČ, R. (I99I) «Nouns in search of a context: A study of nouns with both open-and closed-system characteristics», IRAL - International Review of Applied Linguistics in Language Teaching, 29 (2) pp. 93-II4.

Jiang, F. \& K. Hyland (20I5) "The fact that': Stance nouns in disciplinary writing». Discourse Studies I7 (5) pp. 529-550.

KolhatKar, V. (20I5) «Resolving shell nouns» (University of Toronto).

KolhatKar, V. \& G. Hirst (2OI4) «Resolving Shell Nouns», in A. f. C. Linguistics (ed.), Proceedings of the 2014 Conference on EmpiricalMethods in Natural Language Processing (EMNLP), October 25-29 (Doha, Qatar, Association for Computational Linguistics), pp. 499-5IO. 
Kolhatkar, V., H.Zinsmeister \& G. Hirst (20I3) «Interpreting anaphoric shell nouns using antecedents of cataphoric shell nouns as training data», 2013 Conference on Empirical Methods in Natural Language Processing, I8-2I October 2013 (Seattle, Washington, USA Association for Computational Linguistics), pp. 300-Io.

LANGACKER, R.W. (1987a) «Nouns and verbs», Language, 63, pp. 53-97.

- (1987b) Foundations of cognitive grammar. Vol. I: Theoretical prerequisites, Stanford, Calif., Stanford University Press.

Leech, G.N. (198I) Semantics 2nd ed., Harmondsworth, Penguin.

Mantlik, A. (2OII) «The historical development of shell nouns: A diachronic study of abstract noun constructions in English», unpublished $\mathrm{PhD}$ thesis (LMU Munich).

- (2013) «An etymological analysis of shell nouns», in H. Sauer \& G. Waxenberger (ed.), Recording English, researching English, transforming English, Franfurt/Main, Peter Lang, pp. I33-6I.

Mantuik, A. \& H.-J. Schmid (forthcoming) «That-complementizer omission in $\mathrm{N}+\mathrm{BE}+$ that-clauses - register variation or constructional change?», in Alex Ho-Cheong Leung \& Wim van der Wurff, ed. (2017) The NP in English: Past and Present, Amsterdam, John Benjamins.

PAQuot, M. (2007) "Towards a productively-oriented academic word-list», in J. Waliński, K. Kredens \& S. Goźdź-Roszkowski (ed.), Corpora and ICT in Language Studies. PALC 2005, Frankfurt/Main, Peter Lang, pp. 127-40.

RiberA, J. (2007) «Text deixis in narrative sequences», International Journal of English Studies, 7 (I), pp. I49-68.

Scheler, M. (1977) Der englische Wortschatz, ist ed., Berlin, E. Schmidt.

Schmid, H.-J. (1998) "Constant and ephemeral hypostatization: thing, problem and other shell nouns», in B. Caron (ed.), I6th International Congress of Linguists (Paris, July 22-25 1997, CD-ROM: Elsevier).

- (1999) "Cognitive effects of shell nouns», in K. van Hoek, A. Kibrik \& L. Noordman (ed.), Discourse Studies in Cognitive Linguistics, Berlin, Mouton de Gruyter, pp. III-32.

- (2000) English abstract nouns as conceptual shells: from corpus to cognition, Berlin I New York, Mouton de Gruyter.

- (200I) «Presupposition can be a bluff: How abstract nouns can be used as presupposition triggers", Journal of Pragmatics, 33, pp. 1529-52.

— (2007) «Non-compositionality and of lexico-grammatical chunks: A corpus study of noun phrases with sentential complements as constructions", Zeitschrift für Anglistik und Amerikanistik, 55 (3), pp. 313-40. 
Schmid, H.-J. \& H. KüChenhoff (2OI3) «Collostructional analysis and other ways of measuring lexicogrammatical attraction: Theoretical premises, practical problems and cognitive underpinnings», Cognitive Linguistics, 24 (3), pp. 53I-77.

Schmid, H.-J. \& A. MANTLIK (20I5) «Entrenchment in historical corpora? Reconstructing dead authors' minds from their usage profiles", Anglia, I33 (4), pp. 583-623.

Simonjetz, F. \& A. Roussel (20I6) «Crosslinguistic annotation of German and English shell noun complexes» in S. Dipper, F. Neubarth \& H. Zinsmeister (eds.), Proceedings of the I3th Conference on Natural Language Processing (KONVENS) Bochum, Germany September I9-2I, 2016 (Bochum, Bochumer Linguistische Arbeitsberichte), pp. 265-78.

Stefanowitsch, A. \& S. T. Gries (2003) «Collostructions: investigating the interaction of words and constructions», International Journal of Corpus Linguistics, 8 (2), pp. 209-43.

Traugott, E. C. \& G. Trousdale (2013) Constructionalization and constructional changes, Oxford, Oxford University Press.

Ungerer, F. \& H.-J. Schmid (2006) An introduction to cognitive linguistics, 2nd ed., New York, Longman.

Vendler, Z. (1968) Adjectives and nominalizations, The Hague, Paris, Mouton.

Vergaro, C. (20I5) "Ways of asserting. English assertive nouns between linguistics and the philosophy of language», Journal of Pragmatics, 84, pp. I-I7.

- (2018) Illocutionary shell nouns in English, Berlin: Peter Lang.

Vergaro, C. \& H.-J. Schmid (20I7) «Do the meanings of abstract nouns correlate with the meanings of their complementation patterns? A case study on English commissive shell nouns", Pragmatics \& Cognition, 24 (I), pp. 93-I20.

Wierzbicka, A. (I988) The semantics ofgrammar, Amsterdam/Philadelphia, Benjamins. WinTER, E.O. (1977) «A clause-relational approach to English texts: A study of some predictive lexical items in written discourse», Instructional Science, 6 (I), pp. I-92. 